\title{
Effects of caffeine on renal and pulmonary function in preterm newborn lambs
}

\author{
Kelly J. Crossley ${ }^{1}$, Beth J. Allison', Graeme R. Polglase', Colin J. Morley², Richard Harding ${ }^{3}$, Peter G. Davis², Timothy J.M. Moss', \\ Stuart B. Hooper'
}

INTRODUCTION: Administration of caffeine is associated with a reduction in bronchopulmonary dysplasia, assisted ventilation, patent ductus arteriosus (DA), and cerebral palsy in preterm infants, but the mechanisms are unknown. Our aim was to determine the effects of acute caffeine administration on renal and pulmonary functions in preterm lambs.

METHODS: Lambs were delivered by cesarean section at $\sim 126 \mathrm{~d}$ of gestation and ventilated with a tidal volume of $5 \mathrm{ml} /$ $\mathrm{kg}, 60$ breaths/min and $5 \mathrm{cmH}_{2} \mathrm{O}$ positive end-expiratory pressure. After $30 \mathrm{~min}$, lambs received $40 \mathrm{mg} / \mathrm{kg}$ caffeine i.v. $(n=7)$ or saline (controls; $n=6$ ) over 30 min and were ventilated for $2 \mathrm{~h}$.

RESULTS: Arterial concentrations of caffeine reached $35.9 \pm$ $7.8 \mathrm{mg} / \mathrm{l}$. Urine output and mean heart rate were significantly higher after caffeine treatment than in controls (5.86 \pm 1.95 vs. $0.76 \pm 0.94 \mathrm{ml} / \mathrm{kg}$, area under the curve, $P=0.041$ and $211 \pm 8$ vs. $169 \pm 15$ beats per minute, $P<0.05$, respectively). Heart rate remained higher for the experimental period.

DISCUSSION: Caffeine did not affect pulmonary artery or DA blood flows or other renal, respiratory, or cardiovascular parameters examined. Neonatal administration of caffeine increased heart rate and urine output but had little effect on pulmonary function in ventilated preterm lambs.

P reterm birth, defined as birth before 37 complete weeks of gestation, occurs in $7-12 \%$ of all births in developed countries and accounts for over $70 \%$ of neonatal mortality and morbidity (1). Apnea of prematurity is one of the most common problems encountered in the clinical management of preterm infants, occurring in $85 \%$ of infants born at $<34 \mathrm{wk}$ gestation (2). Apnea of prematurity (usually defined as a cessation of breathing $>15 \mathrm{~s}$ ) is often associated with bradycardia and arterial desaturation (3) and is common in preterm infants because they have immature respiratory control mechanisms. Methylxanthines (theophylline and caffeine) and continuous positive pressure ventilation have been the mainstay for managing apnea in preterm infants for more than $30 \mathrm{y}$ (3). Methylxanthines increase central inspiratory drive and minute ventilation; they also improve $\mathrm{CO}_{2}$ sensitivity, decrease hypoxic depression of breathing, and relax bronchial smooth muscle $(4-6)$. Caffeine is the methyxanthine that is most commonly used to treat apnea because it has a longer half-life, a higher therapeutic index, and lower toxicity than theophylline (7). Caffeine treatment improves dynamic respiratory compliance during the first week after birth in preterm infants with respiratory distress syndrome (8) and improves diaphragmatic contractility $(9,10)$, both of which improve ventilation and gas exchange. At therapeutic concentrations, the actions of caffeine appear to be mediated primarily by competitive antagonism of adenosine (A1 and A2a) receptors (11).

At birth, the airways must be cleared of liquid to allow the entry of air and the onset of pulmonary gas exchange $(10,12,13)$. The process of lung aeration initiates major changes in cardiopulmonary physiology that are essential for the transition to air-breathing after birth, including a large increase in pulmonary blood flow (PBF) and left-to-right shunting through the ductus arteriosus (DA) before it closes (14-17). Failure of the lungs to fully aerate after birth is a common problem in very preterm infants that impedes the transition to postnatal life. As a result, these infants usually require some form of assisted ventilation to survive, but this intervention can initiate or exacerbate lung injury, which can lead to bronchopulmonary dysplasia.

A recent study demonstrated that caffeine therapy for very preterm infants is associated with significant reductions in the duration of assisted ventilation, the incidence of patent DA, and the rate of bronchopulmonary dysplasia, by $\sim 10 \%$, and that it reduces the incidence of cerebral palsy as compared with placebo-treated infants $(18,19)$. Although these are very important outcomes, the mechanisms responsible are unknown. In addition to promoting the stability of respiratory drive, it is possible that caffeine has a direct effect on the lungs, through its diuretic action, leading to improved lung liquid clearance. Following its clearance from the airways, the liquid enters the pulmonary tissue to form perivascular cuffs (20), leading to increased pulmonary interstitial tissue pressure (21). This liquid takes hours to clear from lung tissue $(20,21)$, and sustained high interstitial tissue pressures promotes liquid movement back into the airways $(22,23)$; the presence of pulmonary hypertension may compound this problem. We hypothesized that caffeine would increase urine output, thereby enhancing the rate of pulmonary fluid clearance and improving 
pulmonary function. Our aim was to determine the effect of an acute, high-dose caffeine infusion on renal and pulmonary functions in ventilated preterm lambs.

\section{RESULTS}

Gestational age at birth, birth weight, and wet lung weight or wet/dry lung weight ratio were not significantly different between the caffeine and control groups (Table 1).

\section{Plasma and Urine Caffeine Concentrations}

Arterial plasma caffeine concentrations were significantly elevated in the caffeine-treated lambs within $15 \mathrm{~min}$ of administration of caffeine $(P<0.001$; Figure 1a). The concentrations of caffeine increased further in the 30 -min period after the infusion and then remained around this concentration for the duration of the experiment $(P<0.001$; Figure 1a). Concentrations of caffeine in urine were significantly elevated above control levels within $15 \mathrm{~min}$ of administration of caffeine and increased further in the 30 -min period after the infusion $(P<0.001$; Figure 1a). The urinary caffeine concentration remained elevated for the remainder of the experiment. The concentrations of caffeine in plasma and urine in the control lambs were negligible (Figure 1a).

\section{Renal Function}

Over the experimental period, area under the curve urine output was significantly greater in caffeine-treated lambs (5.86 $\pm 1.95 \mathrm{ml} / \mathrm{kg})$ than in controls $(0.76 \pm 0.94 \mathrm{ml} / \mathrm{kg} ; P=0.041)$ (Figure 1b). At $30 \mathrm{~min}$ after the infusion started, mean urine flow rates were $10.2 \pm 2.5 \mathrm{ml} / \mathrm{kg} / \mathrm{h}$ in caffeine-treated lambs and $5.3 \pm 1.1 \mathrm{ml} / \mathrm{kg} / \mathrm{h}$ in controls. For the following hour, urine flow rates remained high in the caffeine-treated lambs as compared with the controls, (Figure 1b). Urine output for the 30-min period immediately after the cessation of caffeine or saline infusion was significantly greater in both groups of lambs than urine output at $60-90$ and $90-120 \mathrm{~min}$ after the infusion period $(P=0.046)$. The volume of fluid infused into the lambs during the experiment was similar in the two groups (caffeine, $10.3 \pm 1.2 \mathrm{ml} / \mathrm{kg}$; controls, $9.6 \pm 0.33 \mathrm{ml} / \mathrm{kg}$ ).

Glomerular filtration rate was similar in the two groups of lambs (Figure 1c) as was fractional sodium clearance (Figure 1d). Concentrations of sodium, potassium, glucose, and urea in urine and plasma were similar for the two groups, as was the urinary excretion of sodium and potassium (data not shown).

Table 1. Gestational parameters and weights

\begin{tabular}{lcc}
\hline & $\begin{array}{c}\text { Saline control } \\
(n=6)\end{array}$ & $\begin{array}{c}40 \mathrm{mg} / \mathrm{kg} \text { caffeine } \\
(n=7)\end{array}$ \\
\hline Gestational age $(\mathrm{d})$ & $128 \pm 1$ & $128 \pm 1$ \\
Male:female ratio & $3: 3$ & $3: 4$ \\
Body weight $(\mathrm{kg})$ & $3.08 \pm 0.1$ & $3.66 \pm 0.2$ \\
Wet lung weight $(\mathrm{g})$ & $88.7 \pm 7.1$ & $90.2 \pm 5.9$ \\
Wet/dry lung weight ratio & $8.5 \pm 0.6$ & $8.5 \pm 0.5$ \\
\hline
\end{tabular}

Data shown as mean \pm SEM. Statistical analyses were performed using unpaired $t$ test.

\section{Cardiopulmonary Function}

Heart rates were greater in caffeine-treated lambs as compared with controls $(P=0.012$; Figure 2a) $10 \mathrm{~min}$ after infusion onset; heart rates remained elevated for the duration of the experiment in caffeine-treated lambs (Figure 2a). Heart rate increased over the course of the experimental period in caffeine-treated lambs but decreased in the controls $(P=0.007)$. Mean arterial pressure was not different between groups (Figure 2b).

PBF and DA blood flow, pulmonary arterial pressure, and pulmonary vascular resistance (PVR) were not significantly different between groups (Figure $2 \mathrm{c}-\mathrm{e}$ ). In both groups, after the initial increase in PBF and decrease in DA flow, which occurred during the $30-\mathrm{min}$ stabilization period, PBF $(P<0.001)$ decreased and DA flow $(P<0.001)$ increased with time. Mean carotid arterial pressure $(P<0.001)$, mean pulmonary artery pressure $(P<0.001), \mathrm{PaO}_{2}(P=0.004$; Figure $3 \mathrm{a})$, and oxygen saturation $(P=0.024$; Figure $3 b)$ decreased during the experiment in both groups. Conversely, PVR $(P<0.001$; Figure 2e) and $\mathrm{PaCO}_{2}(P=0.014$; Figure $3 \mathrm{~d})$ increased during the experiment in both groups. There were no significant differences in $\mathrm{PaO}_{2}$, percentage oxygen saturation of hemoglobin, $\mathrm{PaCO}_{2}$, or arterial pH between the treatment groups (Figure 3a-d).

\section{Ventilation Parameters}

Dynamic respiratory system compliance and mean airway pressure were not significantly different between the groups (Figure 3e,f). Mean airway pressure $(P=0.018)$ decreased during the stabilization period and then tended to increase in both groups. There were no significant differences in ventilator efficiency index or oxygenation index between the groups (data not shown).

\section{DISCUSSION}

We have demonstrated that intravenous administration of caffeine, sufficient to increase the heart rate and urine output, has a limited effect on renal function and no acute effect on cardiopulmonary function in ventilated preterm lambs. To our knowledge, this is the first study to investigate all of these functional parameters concurrently in ventilated preterm experimental subjects with lung maturation similar to that of infants born around 30-34 wk gestation.

\section{Caffeine Concentration}

We chose a dose of caffeine within the upper end of the range of doses used clinically. The current commonly prescribed dosing regimen for preterm infants with apnea is a loading dose of $10-20 \mathrm{mg} / \mathrm{kg}$ caffeine base intravenously or orally, followed by a daily maintenance dose of $2.5-5 \mathrm{mg} / \mathrm{kg}$ caffeine base (24). This regimen has proven effective for more than $30 \mathrm{y}$ and is sufficient to prevent or decrease apnea and increase respiratory drive (7). The higher dose used in our study is one that may be used to reduce apnea and facilitate extubation in preterm infants being weaned from mechanical ventilation (25). We have demonstrated that concentrations of caffeine are rapidly increased in both plasma $(40 \mathrm{mg} / \mathrm{l})$ and urine $(30 \mathrm{mg} / \mathrm{l})$, 

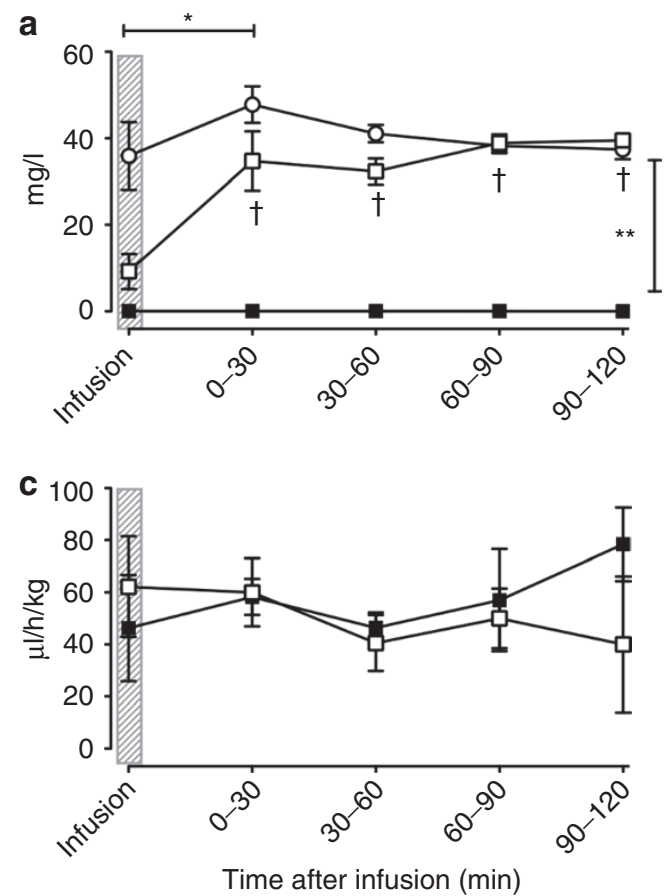
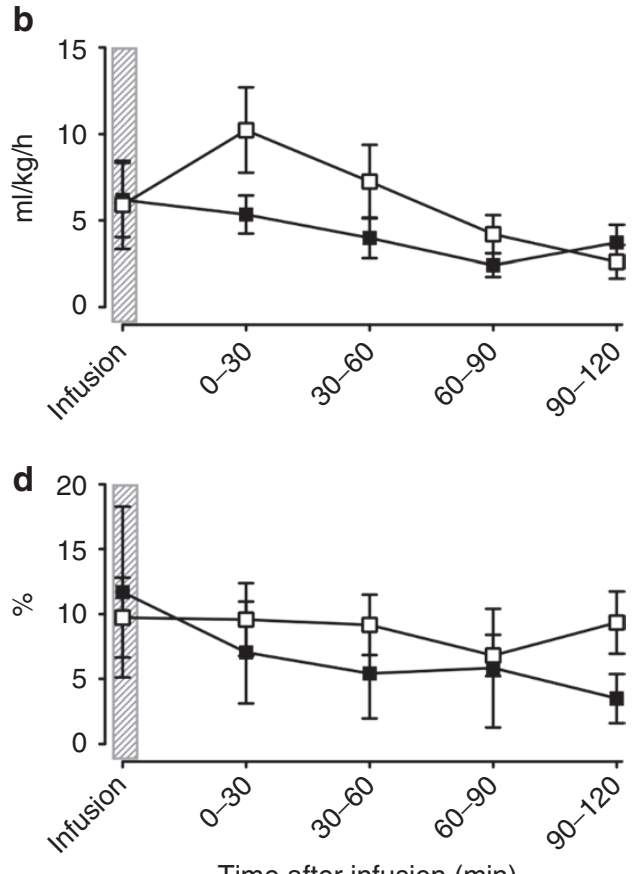

Time after infusion $(\min )$

Figure 1. Data obtained from caffeine-treated (white symbols) and control (black symbols) lambs over the experimental period. The shaded bars show the period of caffeine infusion. (a) Concentrations of caffeine in plasma (circles) and urine (squares); ${ }^{*}$ indicates significant difference in caffeine concentrations at time points indicated by bar $(P<0.001)$; $†$ indicates significant difference in urinary concentrations of caffeine at those time points compared with the infusion period $(P<0.001) ; * *$ indicates significant difference in plasma and urinary concentrations of caffeine between the treatment groups $(P<0.001)$; (b) urine flow rates $(P=0.041)$; (c) glomerular filtration rate (not significant); (d) urinary fractional sodium clearance (not significant). Urine flow rates over the experimental period were assessed by measuring the area under the curve and differences between the groups were compared using an unpaired $t$ test $(P=0.041)$. Values were obtained at 30-min intervals, and data are presented as mean \pm SEM.
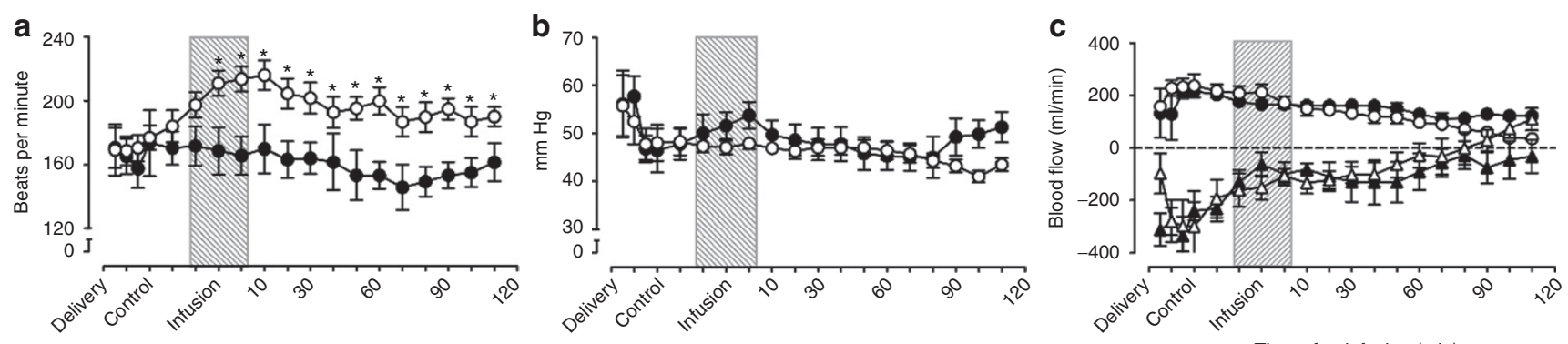

d

e
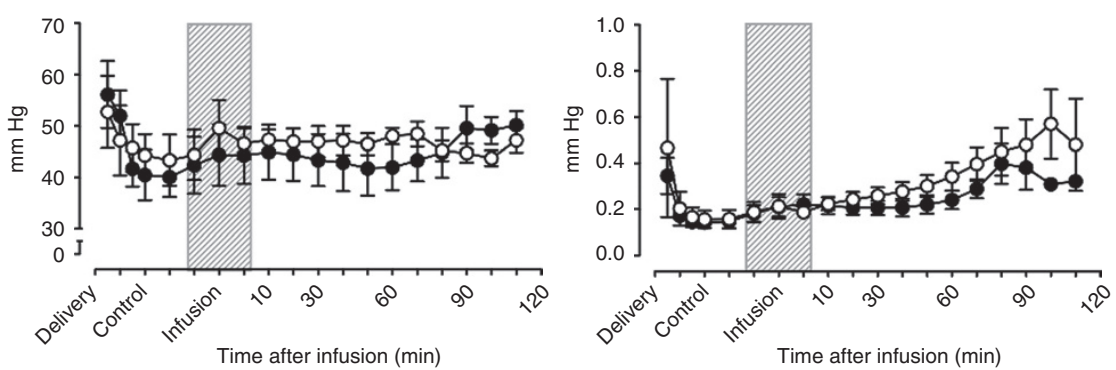

Figure 2. Physiological data obtained in caffeine-treated (white symbols) and control (black symbols) lambs. The shaded bars show the period of caffeine infusion. (a) Heart rate; * indicates significant difference between caffeine-treated and control lambs at those time points during the experiment $(P=0.012)$. Heart rate increased over the course of the experiment in the caffeine group but decreased in the saline control group $(P=0.007) ;(b)$ mean arterial pressure decreased $(P<0.001)$ during the experiment in both the groups; (c) left pulmonary artery blood flow (circles) decreased and ductus arteriosus blood flow (triangles) increased during the experiment in both groups $(P<0.001)$; (d) pulmonary artery pressure decreased $(P<0.001)$ after delivery; and $(\mathbf{e})$ pulmonary vascular resistance increased $(P<0.001)$ in both groups. The figure shows values recorded just after delivery, during the 30-min control period, during the 30-min infusion period, and at regular intervals after the infusion. Data are presented as mean \pm SEM. 

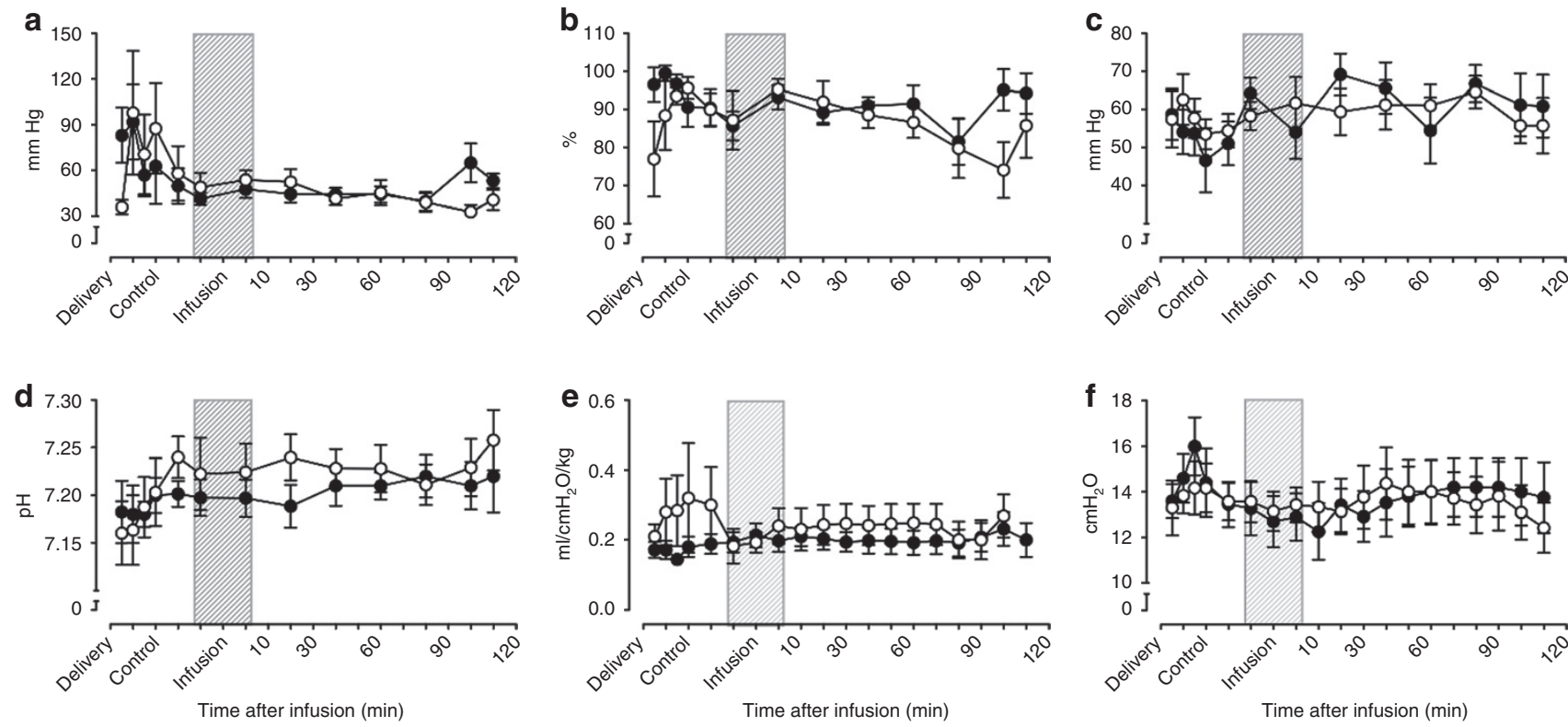

Figure 3. Comparison between caffeine-treated (white symbols) and control (black symbols) lambs for (a) partial pressure of oxygen in arterial blood, which significantly decreased $(P=0.004)$; (b) arterial blood saturation, which decreased $(P=0.024)$; (c) partial pressure of carbon dioxide in arterial blood, which increased $(P=0.01)$; (d) arterial $\mathrm{pH}$, which was unchanged during the experiment in either group; (e) dynamic respiratory compliance; (f) mean airway pressure, which decreased over the experimental period in both the groups $(P=0.018)$. The shaded bars show the period of caffeine infusion. The figure shows values recorded just after delivery, during the 30-min control period, during the 30-min infusion period, and at regular intervals after the infusion. Data are presented as mean \pm SEM.

reaching a maximum within 60 min of commencing the infusion; these high concentrations were maintained for the remainder of the experimental period. The plasma concentrations of caffeine detected are comparable with the therapeutic range for the treatment of apnea in preterm infants $(5-50 \mathrm{mg} / \mathrm{l})$ (9). We anticipated maintenance of plasma caffeine concentrations after our 30-min infusion because the half-life of caffeine is estimated to be $60-140 \mathrm{~h}$ in preterm infants (26).

\section{Renal Function}

The methylxanthine theophylline has been shown to improve renal function during the first $2 \mathrm{~d}$ after birth in very preterm infants with respiratory distress syndrome (27) and the renal effects of methylxanthines appear to be dose- and time-related in newborn rabbits (28). We hypothesized that caffeine would reduce liquid accumulation in the lungs through its diuretic action, therefore facilitating improved lung function. Although we found no evidence of a change in pulmonary water content (wet/dry lung weight ratio) at the end of the experiment or pulmonary function throughout the experiment, caffeine did increase urine flow. At 30-60 min after beginning the caffeine infusion, urine flow rates were approximately double those measured in control lambs. As a result, caffeine-treated lambs lost $\sim 5 \mathrm{ml} / \mathrm{kg}$ of liquid more than saline-treated lambs over the 2-h experiment.

Apart from an increase in urine flow, there were no changes in glomerular filtration rate, urinary excretion of sodium and potassium, or the fractional clearance of sodium, indicating minimal effects on renal function. Previous studies in preterm infants have shown that administration of caffeine increased urine flow rate, increased creatinine clearance (as an indicator of glomerular filtration rate), and affected other renal functions (including urinary sodium excretion) (29). However, these effects were observed more than $12 \mathrm{~h}$ after commencing caffeine and occurred in response to a much lower dose $(7.5 \mathrm{mg} /$ $\mathrm{kg}$ ) than we used. Presumably, therefore, the effects of caffeine on aspects of renal function other than urine output take some time to manifest.

\section{Cardiovascular Function}

The physiological responses to caffeine infusion observed in our study included an increase in heart rate and urine output. However, these responses did not translate into any other physiological changes, including effects on mean arterial pressure, pulmonary artery pressure, PVR, or blood-gas parameters. These findings are in contrast to other studies that found intravenous caffeine increased cardiac output and blood pressure in preterm infants, around $60 \mathrm{~min}$ after administration, even at a lower dose ( $5 \mathrm{mg} / \mathrm{kg}$ caffeine base) than we used (30). In dogs, methylxanthines decreased airway resistance, pulmonary artery pressure, and PVR, and increased lung compliance and PBF (31,32). Again, these previously observed changes presumably take some time to manifest and our 2-h experimental period may not have been long enough to induce these additional physiological responses.

The recently reported clinical trial of infants treated with caffeine found that administration of caffeine resulted in infants being less likely to require pharmacological or surgical closure of a patent DA (18). Therefore, we considered that caffeine might have a direct effect on the pulmonary vasculature and DA. 
However, we found no difference in PBF or blood flow through the DA between caffeine and saline-treated lambs. Our findings are consistent with those of a recent study demonstrating that, in isolated DA from fetal sheep, caffeine had no direct effect on vessel contractility (33). The temporal changes in PBF and DA blood flow we observed are consistent with our previous studies, which have shown that immediately after birth retrograde flow (left-to-right shunting) through the DA contributes to the increase in PBF. Subsequently, PBF gradually decreases with time, mostly because of a gradual reduction in the contribution of left-to-right flow through the DA as it closes (17).

\section{Pulmonary Function}

In preterm infants, caffeine has been shown to increase breathing frequency, decrease the number of apneic events, and reduce $\mathrm{PaCO}_{2}$, the need for mechanical ventilation, and the duration of ventilation $(4,34)$. Caffeine may also improve ventilation in preterm infants by improving or stabilizing diaphragm muscle function and preventing diaphragm fatigue (9). Our experimental design deliberately obviated our ability to determine effects on breathing frequency or diaphragm function, as the lambs were anesthetized and mechanically ventilated because we wanted to avoid the confounding effects of caffeine on respiratory drive.

Caffeine has been shown to improve respiratory compliance and reduce supplemental oxygen requirements during the first postnatal week in preterm infants with respiratory distress syndrome, $24 \mathrm{~h}$ after treatment (35). Improvement in lung mechanics has previously been shown to occur in infants with bronchopulmonary dysplasia within $1 \mathrm{~h}$ of caffeine therapy (36). We did not found any changes in dynamic lung compliance and it is unlikely that airway resistance was altered in our lambs treated with caffeine. Further, a study in preterm baboons treated with caffeine demonstrated improvement in lung function and a twofold increase in urine output in the initial $24 \mathrm{~h}$ after birth (37). Our study shows that these established effects of neonatal administration of caffeine are not a consequence of the immediate, acute effects of the treatment. Our inability to detect an effect of caffeine on lung water content suggests that the physiological benefit of administration of caffeine observed in previous studies is not a consequence of improved liquid clearance from the neonatal lungs.

\section{Experimental Model}

We chose to investigate functional parameters concurrently in ventilated preterm experimental subjects with lung maturation similar to that of infants born around 30-34 wk gestation. At this gestational age ( $~ 126 \mathrm{~d}$ gestation) lambs have very immature lungs and are not viable without respiratory support. This study was purposely designed to understand the physiological concepts involved in the relationship of caffeine to renal, and pulmonary functions. We were not trying to exactly replicate the protocols and procedures used in the clinical setting, instead we were trying to answer a specific scientific question that is relevant to and improves our understanding of the clinical use of caffeine in neonates.

\section{Conclusion}

We conclude that intravenous administration of caffeine, which causes an increase in heart rate and urine output, has no effect on cardiopulmonary function during $2 \mathrm{~h}$ of ventilation in preterm lambs. Findings from this study demonstrate that acute, high-dose caffeine treatment in ventilated preterm lambs is unlikely to influence cardiopulmonary function or exacerbate poor outcomes in the short term. This suggests that the beneficial effects of caffeine in preterm infants may be central, rather than pulmonary, in origin.

\section{METHODS}

\section{Experimental Protocol}

The relevant Monash University animal ethics committee approved all experimental procedures. Aseptic surgery was conducted on 13 pregnant ewes at $\sim 122 \pm 2 \mathrm{~d}$ (mean \pm SD) of gestation (term is $\sim 147$ d) using established techniques (16). Briefly, catheters were inserted into a fetal carotid artery and jugular vein, the amniotic sac and left pulmonary artery; ultrasonic flow probes (Transonic Systems, Ithaca, $\mathrm{NY}$ ) of $4 \mathrm{~mm}$ diameter were placed around the left pulmonary artery and DA. After recovery from surgery, ewes were kept in individual cages. Fetal well-being was monitored daily by measuring fetal $\mathrm{PaO}_{2}$, $\mathrm{PaCO}_{2}, \mathrm{pH}$, and percentage oxygen saturation of hemoglobin (ABL30, Radiometer, Denmark). Mean arterial blood pressure, pulmonary arterial pressure, and pulmonary and DA blood flows were recorded digitally (ADInstruments, N.S.W., Australia).

\section{Delivery and Ventilation}

At $126 \pm 2 \mathrm{~d}$ of gestation, ewes and fetuses were anesthetized by maternal administration of sodium thiopentone ( $100 \mathrm{mg}$ i.v) followed by $2 \%$ isoflurane in $\mathrm{O}_{2}$ and the fetal head and neck exposed via caesarean section. The fetal trachea was orally intubated with a $3.5 \mathrm{~mm}$ cuffed tube and lung liquid was drained passively before the umbilical cord was clamped and cut. Lambs were then delivered, dried, weighed, and placed under a radiant heater and ventilated (Babylog 8000+; Dräger, Germany; in volume guarantee mode) with an expired tidal volume of $5 \mathrm{ml} / \mathrm{kg}$, ventilator rate of 60 breaths/ min, a positive end-expiratory pressure of $5 \mathrm{cmH}_{2} \mathrm{O}$, and an initial fraction of inspired oxygen of 1.0. Expiratory time and initial fraction of inspired oxygen were altered (depending on blood-gas values) to maintain arterial $\mathrm{pH}$ between 7.30 and $7.45, \mathrm{PaCO}_{2}$ between 40 and $55 \mathrm{~mm} \mathrm{Hg}$, and percentage oxygen saturation of hemoglobin between 90 and 95\%. Arterial blood gases $\left(\mathrm{pH}, \mathrm{PaCO}_{2}, \mathrm{PaO}_{2}\right.$, and percentage oxygen saturation of hemoglobin) were collected and adjusted for body temperature every $5 \mathrm{~min}$ for the first $20 \mathrm{~min}$, then every $10 \mathrm{~min}$ for the rest of the experimental period. Lambs were sedated (Alfaxalone, $15 \mathrm{mg} / \mathrm{h}$ i.v, Jurox, Australia) in 5\% dextrose $(6 \mathrm{ml} / \mathrm{h}$ i.v. $)$ to prevent spontaneous breathing. All lambs were ventilated for a 30-min stabilization period, during which a bladder catheter was inserted to permit timed collections of urine. An incision was made below the umbilical cord in the abdomen and the bladder was located by blunt dissection. A catheter (size 5.0 French) was secured into the bladder using a purse-string suture.

Following the initial 30-min ventilation period, caffeine base (Auspman, WA, Australia) in a $10 \mathrm{mg} / \mathrm{ml}$ solution was administered intravenously at $40 \mathrm{mg} / \mathrm{kg}(n=7)$ over a 30 -min period. Control lambs $(n=6)$ were infused with saline over the same period. Lambs were then ventilated for a further $120 \mathrm{~min}$.

At $126 \mathrm{~d}$ gestation lambs have very immature lungs and are not viable without respiratory support. As this study was purposely designed to understand the physiological concepts involved in the relationship between caffeine and renal and pulmonary functions, we did not administer antenatal glucocorticoids or postnatal surfactant.

\section{Analytical Methods}

Renal function. Serial urine samples were collected after the initial stabilization period over 30-min intervals throughout the experiment. 
An arterial blood sample was collected midway between successive urine collections. Blood samples were transferred immediately to lithium heparin tubes and centrifuged at $4^{\circ} \mathrm{C}$ and 2,500 rpm. Plasma and urine samples were frozen at $-20^{\circ} \mathrm{C}$ for subsequent measurement of caffeine, sodium, potassium, creatinine, glucose, and urea (Synchron CX5 Delta clinical analyzer, Beckman Coulter, Brea, CA). The following parameters were calculated:

1. Urine flow rate $(\mathrm{ml} / \mathrm{h} / \mathrm{kg})$

2. Glomerular filtration rate $(\mu \mathrm{l} / \mathrm{h} / \mathrm{kg}$; assessed using creatinine clearance); glomerular filtration rate $=$ urine flow rate $\times$ urine $_{\text {creatinine }} /$ plasma $_{\text {crs }}$

3. Urinary fractional sodium clearance (\%); urinary fractional sodium clearance $=\left(\right.$ excretion rate $_{\text {sodium }} /$ filtered $\left._{\text {sodium }}\right) \times 100$;

where: excretion rate ${ }_{\text {sodium }}=$ urine flow rate $\times$ urine $_{\text {sodium }}$; and filtered ${ }_{\text {so. }}$ dium $=$ glomerular filtration rate $\times$ plasma $_{\text {sodium }}$.

Pulmonary function. Mean arterial pressure, left pulmonary artery pressure and blood flow, and DA blood flow were recorded continuously. PVR was calculated using the formula PVR = Ppa $-\mathrm{Pla} / \mathrm{Qp}$, where $\mathrm{Ppa}$ is pulmonary arterial pressure, Pla is left atrial pressure and $\mathrm{Qp}$ is flow through the left pulmonary artery; Pla was assumed to be $9 \mathrm{~mm} \mathrm{Hg}(16,38)$.

Ventilation parameters, including dynamic respiratory compliance and mean airway pressure were recorded every $10 \mathrm{~min}$. Lung tissue samples were collected for determination of the wet/dry lung weight ratio as an index of interstitial tissue fluid content; samples were dried (at $60^{\circ} \mathrm{C}$ ) and weighed daily until there was no change in the dry weight over $3 \mathrm{~d}$.

\section{Statistical Analysis}

Concentrations of caffeine in plasma and urine, concentrations of electrolytes in urine and plasma, blood-gas values, and renal and pulmonary function values were analyzed using two-way repeated measures ANOVA with treatment (caffeine vs. saline infusion) and time as factors. If significant effects of treatment group and/or time were found, Fisher's test of least significant difference was used, post hoc, to identify the time points at which there were differences between the groups. Urine flow rates over the experimental period were assessed by measuring the area under the curve and differences between groups were compared using an unpaired $t$ test. An unpaired $t$ test was used to compare gestational age at birth, birth weight, wet lung weight, wet/dry lung weight ratio, and the volume of fluids infused during the experiment between the caffeine and saline control groups. Data are presented as mean \pm SEM. The level of statistical significance was $P<0.05$.

\section{ACKNOWLEDGMENTS}

The authors acknowledge the expert technical assistance of A. Baburamani, A. Satragno, V. Zahra, A. Thiel, K. Rodgers, and D. Chalmers.

\section{STATEMENT OF FINANCIAL SUPPORT}

This study was supported by the National Health and Medical Research Council, Australia (Grant 384100), and the Victorian government's Operational Infrastructure Support Program.

\section{REFERENCES}

1. Moss TJ. Respiratory consequences of preterm birth. Clin Exp Pharmacol Physiol 2006;33:280-4.

2. Barrington K, Finer N. The natural history of the appearance of apnea of prematurity. Pediatr Res 1991;29(4 Pt 1):372-5.

3. Martin RJ, Abu-Shaweesh JM, Baird TM. Apnoea of prematurity. Paediatr Respir Rev 2004;5:Suppl A:S377-82.

4. Davi MJ, Sankaran K, Simons KJ, Simons FE, Seshia MM, Rigatto H. Physiologic changes induced by theophylline in the treatment of apnea in preterm infants. J Pediatr 1978;92:91-5.

5. Becker AB, Simons KJ, Gillespie CA, Simons FE. The bronchodilator effects and pharmacokinetics of caffeine in asthma. N Engl J Med 1984;310:743-6.

6. Greenough A, Elias-Jones A, Pool J, Morley CJ, Davis JA. The therapeutic actions of theophylline in preterm ventilated infants. Early Hum Dev 1985;12:15-22.
7. Aranda JV, Cook CE, Gorman W, et al. Pharmacokinetic profile of caffeine in the premature newborn infant with apnea. J Pediatr 1979;94:663-8.

8. Laubscher B, Greenough A, Dimitriou G. Comparative effects of theophylline and caffeine on respiratory function of prematurely born infants. Early Hum Dev 1998;50:185-92.

9. Aranda JV, Turmen T. Methylxanthines in apnea of prematurity. Clin Perinatol 1979;6:87-108.

10. Harding R, Hooper SB. Regulation of lung expansion and lung growth before birth. J Appl Physiol 1996;81:209-24.

11. Fredholm BB, Bättig K, Holmén J, Nehlig A, Zvartau EE. Actions of caffeine in the brain with special reference to factors that contribute to its widespread use. Pharmacol Rev 1999;51:83-133.

12. Hooper SB, Harding R. Fetal lung liquid: a major determinant of the growth and functional development of the fetal lung. Clin Exp Pharmacol Physiol 1995;22:235-47.

13. Hooper SB, Kitchen MJ, Siew ML, et al. Imaging lung aeration and lung liquid clearance at birth using phase contrast X-ray imaging. Clin Exp Pharmacol Physiol 2009;36:117-25.

14. Rudolph AM. Fetal and neonatal pulmonary circulation. Annu Rev Physiol 1979;41:383-95.

15. Heymann MA. Control of the pulmonary circulation in the fetus and during the transitional period to air breathing. Eur J Obstet Gynecol Reprod Biol 1999;84:127-32.

16. Polglase GR, Wallace MJ, Grant DA, Hooper SB. Influence of fetal breathing movements on pulmonary hemodynamics in fetal sheep. Pediatr Res 2004;56:932-8.

17. Crossley KJ, Allison BJ, Polglase GR, Morley CJ, Davis PG, Hooper SB. Dynamic changes in the direction of blood flow through the ductus arteriosus at birth. J Physiol (Lond) 2009;587(Pt 19):4695-704.

18. Schmidt B, Roberts RS, Davis P, et al. Caffeine therapy for apnea of prematurity. N Engl J Med 2006;354:2112-21.

19. Schmidt B, Roberts RS, Davis P, et al. Long-term effects of caffeine therapy for apnea of prematurity. N Engl J Med 2007;357:1893-902.

20. Bland RD. Dynamics of pulmonary water before and after birth. Acta Paediatr Scand Suppl 1983;305:12-20.

21. Miserocchi G, Poskurica BH, Del Fabbro M. Pulmonary interstitial pressure in anesthetized paralyzed newborn rabbits. J Appl Physiol 1994;77:2260-8.

22. Siew ML, Te Pas AB, Wallace MJ, et al. Positive end-expiratory pressure enhances development of a functional residual capacity in preterm rabbits ventilated from birth. J Appl Physiol 2009;106:1487-93.

23. Siew ML, Wallace MJ, Kitchen MJ, et al. Inspiration regulates the rate and temporal pattern of lung liquid clearance and lung aeration at birth. J Appl Physiol 2009;106:1888-95.

24. Comer AM, Perry CM, Figgitt DP. Caffeine citrate: a review of its use in apnoea of prematurity. Paediatr Drugs 2001;3:61-79.

25. Steer P, Flenady V, Shearman A, et al. High dose caffeine citrate for extubation of preterm infants: a randomised controlled trial. Arch Dis Child Fetal Neonatal Ed 2004;89:F499-503.

26. Lee TC, Charles B, Steer P, Flenady V, Shearman A. Population pharmacokinetics of intravenous caffeine in neonates with apnea of prematurity. Clin Pharmacol Ther 1997;61:628-40.

27. Cattarelli D, Spandrio M, Gasparoni A, Bottino R, Offer C, Chirico G. A randomised, double blind, placebo controlled trial of the effect of theophylline in prevention of vasomotor nephropathy in very preterm neonates with respiratory distress syndrome. Arch Dis Child Fetal Neonatal Ed 2006;91:F80-4.

28. Gouyon JB, Arnaud M, Guignard JP. Renal effects of low-dose aminophylline and enprofylline in newborn rabbits. Life Sci 1988;42:1271-8.

29. Gillot I, Gouyon JB, Guignard JP. Renal effects of caffeine in preterm infants. Biol Neonate 1990;58:133-6.

30. Soloveychik V, Bin-Nun A, Ionchev A, Sriram S, Meadow W. Acute hemodynamic effects of caffeine administration in premature infants. J Perinatol 2009;29:205-8.

31. Quimby CWJ, Aviado DMJ, Schmidt CF. The effects of aminophylline and other xanthines on the pulmonary circulation. J Pharmacol Exp Ther 1958;122:396-405. 
32. Oskoui M, Aviado DM, Bellet S. Bronchopulmonary effects of caffeine in the anesthetized dog. Respiration 1970;27:63-73.

33. Clyman RI, Roman C. The effects of caffeine on the preterm sheep ductus arteriosus. Pediatr Res 2007;62:167-9.

34. Gerhardt T, McCarthy J, Bancalari E. Aminophylline therapy for idiopathic apnea in premature infants: effects on lung function. Pediatrics 1978;62:801-4.

35. Laubscher B, Greenough A, Dimitriou G. Comparative effects of theophylline and caffeine on respiratory function of prematurely born infants. Early Hum Dev 1998;50:185-92.
36. Davis JM, Bhutani VK, Stefano JL, Fox WW, Spitzer AR. Changes in pulmonary mechanics following caffeine administration in infants with bronchopulmonary dysplasia. Pediatr Pulmonol 1989;6:49-52.

37. Yoder B, Thomson M, Coalson J. Lung function in immature baboons with respiratory distress syndrome receiving early caffeine therapy: a pilot study. Acta Paediatr 2005;94:92-8.

38. Polglase GR, Morley CJ, Crossley KJ, et al. Positive end-expiratory pressure differentially alters pulmonary hemodynamics and oxygenation in ventilated, very premature lambs. J Appl Physiol 2005;99: 1453-61. 